\title{
Postgraduate Course: Table of Contents
}

\author{
Supported in part by Bayer HealthCare Pharmaceuticals
}

\section{Diagnostic Imaging in 2009: Update on the Evidence-Based Practice of Pediatric Imaging \\ Issues in Abdomen, Chest, Musculoskeletal and Neuroimaging}

Kimberly E. Applegate, MD, MS, Course Director

The role of imaging in pyloric stenosis

Marta Hernanz-Schulman, MD S134

Intussusception in children: evidence-based diagnosis and treatment

Kimberly E. Applegate, MD, MS S140

Optimizing the role of imaging in appendicitis

Andrea S. Doria, MD S144

Imaging choices in inflammatory bowel disease

Sudha A. Anupindi, MD S149

Pancreatitis and the role of US, MRCP and ERCP

Kassa Darge, MD, PhD S153

Abdominal trauma imaging: imaging choices and appropriateness

Carlos J. Sivit, MD S158

Special focus session on malrotation: definition, variability, and the role of imaging

Kimberly E. Applegate, MD, MS, Alan Daneman, MD, Stephen B. Shew, MD, David K. Yousefzadeh, MD S161

What imaging should we perform for the diagnosis and management of pulmonary infections?

Sjirk J. Westra, MD S178

What is the role of imaging in asthma and foreign body aspiration?

Brent H. Adler, MD

Evaluation of non-vascular mediastinal masses in infants and children: an evidence-based practical approach Edward Y. Lee, MD, MPH S184

What is the optimal imaging for vascular rings and slings?

Lorna P. Browne, MB BCH BAO, FFRCSI S191
The role of MRI and $\mathrm{CT}$ in congenital heart disease Rajesh Krishnamurthy, MD S196

What is the evidenced based role of US in evaluating the fetus?

Dorothy I. Bulas, MD S205

The growing role of MR imaging in the fetus Judy A. Estroff, MD S209

The role of radiographs and US in developmental dysplasia of the hip: how good are they?

Marc S. Keller, MD S211

What is the optimal imaging of osteonecrosis, perthes, and bone infarcts?

Diego Jaramillo, MD, MPH S216

Impact of obesity in the diagnosis of SCFE and knee problems in obese children

Ricardo Restrepo, MD S220

How should we image skeletal injuries in child abuse?

Rick R. Van Rijn, MD, PhD S226

Imaging of non-accidental head injury?

Yutaka Sato, MD S230

Imaging strategies for new onset seizures

Timothy N. Booth, MD S236

What is the role of imaging in sinusitis?

Yoshimi Anzai, MD, MPH S239

Spinal dysraphism: categorizing risk to optimize imaging

L. Santiago Medina, MD S242

Role of imaging in scoliosis

Geetika Khanna, MBBS S247 